\title{
Age trajectories of disability in instrumental activities of daily living and disability-free life expectancy among middle-aged and older adults in Taiwan: an 11-year longitudinal study
}

\author{
Wen-Ling Liao ${ }^{1}$ and Yu-Hung Chang ${ }^{2^{*}}$ (i)
}

\begin{abstract}
Background: This study aims to identify the age trajectories of disability in instrumental activities of daily life (IADLs) over 11 years and their correlates, and to estimate disability-free life expectancy for identified trajectory groups in middle-aged and older adults.

Methods: We included 3118 participants aged 50 and over without IADL limitations at baseline from the Taiwan Longitudinal Study in Aging, followed across 1996-2007. We used group-based trajectory models to identify age trajectories of IADL disability, and multiple logistic regressions to examine their correlates. Sullivan method was used to compute IADL disability-free life expectancy for trajectory groups at different ages.
\end{abstract}

Results: We identified two trajectories groups: $67.7 \%$ of participants classified as the late-onset group and 32.3\% as the early-onset group. Female (adjusted odds ratio [aOR]: 1.93, 95\% confidence interval [95\% Cl]: 1.54, 2.41), not being employed (aOR: 1.30, 95\% Cl: 1,08, 1,56), poor/fair self-rated health (aOR: 1.31, 95\% Cl:1.09, 1.58), hypertension (aOR: 1.32, 95\% Cl: 1.07, 1.63), diabetes mellitus (aOR: 2.29, 95\% Cl: 1.72, 3.07), arthritis (aOR: 1.42, 95\% Cl: 1.11, 1.81), stroke (aOR: $2.21,95 \% \mathrm{Cl}: 1.04,4.70$ ), and one-point increase in a 10-item depression scale (aOR: $1.04,95 \%$ Cl: 1.02, 1.06) were associated with early-onset of disability, whereas higher education (aOR: 0.59, 95\% Cl: 0.42, 0.81), regular exercise (aOR: $0.76,95 \% \mathrm{Cl}: 0.62,0.93$ ), and participating voluntary or club activities (aOR: $0.78,95 \%$ Cl: $0.65,0.93$ ) related to the late-onset. IADL disability-free life expectancies at 65 years old in the late-onset group were 15.6 years for women and 14.4 for men, respectively, comprising 56.6 and $64.2 \%$ of their remaining life, whereas those of the early-onset group were 4.8 and 4.6 years for women and men respectively, comprising 22.5 and $27.2 \%$ of remaining life.

Conclusions: Early-onset of IADLs disability may correlate to chronic conditions, and engagement in employment, exercise, and social participation were associated with a reduced risk of early disability in IADLs.

Keywords: Disability, Age trajectory, IADL, Middle-aged and older adults, Exercise, Social participation

\footnotetext{
* Correspondence: yuhungc@gmail.com

${ }^{2}$ Department of Public Health, China Medical University, No. 100, Sec. 1 , Jingmao Rd., Beitun Dist., Taichung City 406, Taiwan

Full list of author information is available at the end of the article
}

(c) The Author(s). 2020 Open Access This article is licensed under a Creative Commons Attribution 4.0 International License, which permits use, sharing, adaptation, distribution and reproduction in any medium or format, as long as you give appropriate credit to the original author(s) and the source, provide a link to the Creative Commons licence, and indicate if changes were made. The images or other third party material in this article are included in the article's Creative Commons licence, unless indicated otherwise in a credit line to the material. If material is not included in the article's Creative Commons licence and your intended use is not permitted by statutory regulation or exceeds the permitted use, you will need to obtain permission directly from the copyright holder. To view a copy of this licence, visit http://creativecommons.org/licenses/by/4.0/ The Creative Commons Public Domain Dedication waiver (http://creativecommons.org/publicdomain/zero/1.0/) applies to the data made available in this article, unless otherwise stated in a credit line to the data. 


\section{Background}

Advances in health care have increased human life expectancy. Longer life span, however, does not ensure an extended period of healthy time and good quality of life. Disabilities become more severe with increasing age [13]. Due to the high prevalence of disabilities among older adults, accelerated aging countries will suffer from increasing social and economic burdens [4]. The older population aged 65 and above in Taiwan has risen from $7.1 \%$ in 1993 to $14.5 \%$ in 2018 and will exceed $20.7 \%$ in 2026 [5]. Older people need to retain their ability to live independently in the community because the shrinking workforce may reduce the society's financial capacity and care provision for them.

The World Health Organization has defined disability as negative outcomes resulting from interactions between individuals and their surrounding environment [6]. Disability is an umbrella concept that brings together physical impairments, activity limitations and participation restrictions influenced by contextual factors at the personal and environmental levels. Among older people, difficulty in activities of daily living (ADLs) is one of the most commonly assessed aspects of disability, since activities is the element of participation that determine the extent of participation and the way of interaction between persons with limitations and their living environment. Basic ADLs (BADLs) are the most basic self-care functions essential for an independent life and are mainly activities carried out at home; in contrast, instrumental ADLs (IADLs) tend to have a greater cognitive component, involve more interaction with one's environment, and emphasize community activities [7, 8]. Compared with BADLs, IADLs more involve complicated cognitive and physical skills. As functions decline, IADL impairments usually precede BADL deficits [9]. In this case, analyzing functional decline in IADLs can help predict subsequent disability in BADLs.

Previous studies have examined disability among older adults. The prevalence of ADL disability and IADL disability among Taiwanese aged 65 years or older was $12-$ $14 \%$ and $45-50 \%$, respectively [10]. However, functional decline and preceding factors are common in middleaged [11]. Early onset of disability may confer premature mortality and longer lifetime living with disability and higher costs in health care [12]. However, a prolonged lifespan in the aging population may not necessarily extend the duration of disability [13], as long as modifiable risk factors that lead to disability are intervened [14]. Therefore, it is crucial to observe functional changes from independence to the onset of disability and identify correlates of the functional decline at a younger age in the clinical and policy context.

The current study had the following aims: (a) to use group-based modeling methods to explore the development process of IADL disability over time, and to determine different IADL disability trajectory groups among the representative population of Taiwan aged 50 and over; (b) to examine associations of protective or risk factors at baseline with identified trajectory groups; (c) to compare the number of years of IADL disabilityfree life relative to total life expectancy and the extent of disability expansion or compression among the identified trajectory groups.

\section{Methods}

\section{Data sources}

We used data from the Taiwan Longitudinal Study in Aging (TLSA), initiated in 1989, with a representative sample including 4049 participants aged $\geq 60$ years living in the community or institutions [15]. Five follow-up surveys were conducted in 1993, 1996, 1999, 2003, and 2007. Another 2462 participants aged 50-66 years were introduced in 1996 to supplement the loss of samples from death or loss to follow-up between 1989 and 1996, and to create a representative middle-aged sample $\geq 50$ years of age. Participants were interviewed at home or via telephone. Response rates for all survey waves were over $80 \%$. This study focused on middle-aged and older adults and examined survey data from 1996 onward. To have a clear causal relationship between baseline risk (or protective) factors and the subsequent onset of IADL disability, we excluded participants who already had IADL disabilities $(n=1760)$ or were living in institutions ( $n=13)$ at baseline; participants who had only completed one of the four survey waves $(n=240)$ were also excluded due to the inability to measure changes in their IADLs. Our baseline analytical sample included 3118 respondents aged $\geq 50$ years living in the community. In the last wave (2007), 2301 were alive and interviewed, 178 (5.7\%) were alive but lost to follow up, and 639 (20.49\%) had died before the last wave. Weights were provided to combine the original and supplemental cohorts to ensure the total group of 5131 participants was representative of individuals aged $\geq 50$ years in Taiwan.

\section{Assessment of disability}

The IADL measurement in TLSA was adapted from the Lawton's IADL scale [8]; the Chinese version of the scale was reported to have established validity and reliability [16]. Respondents of TLSA were asked the question: "If you were to carry out the following tasks by yourself, would you have any difficulty with these tasks?" The examined activities were shopping, managing finances, taking public transportation, doing heavy housework, doing light housework, and telephoning. In the original questions, the difficulty level for each IADL activity was assessed using a 4-point scale ( $0=$ no difficulty, $1=a$ little difficulty, 2 = very difficulty, 3 = unable to carry out). 
In this study, responses were dichotomized to no difficulty (0) and some difficulty (1). IADL disability was defined as experiencing some difficulty carrying out one of the examined IADL tasks. Cronbach's alpha of the 6task IADL used in this study ranged from .82 to .92, demonstrating good internal consistency.

\section{Assessment of covariates}

To examine factors affecting IADL disability trajectories, we collected personal baseline information from the 1996 survey. Demographics and socioeconomic status included age, sex, education level, ethnicity, place of residence, marital status, employment, satisfaction of economic status and housing tenure. Health-related behaviors comprised smoking, drinking alcohol, betel nut chewing, leisure-time exercise, habitual eating of breakfast, and receiving of health checks in the previous three years. Health conditions and comorbidities included history of hospitalization during the past year, self-rated health, self-reported visual impairment and hearing loss, and 15 self-reported chronic diseases or conditions: hypertension, diabetes, heart disease, stroke, cancer, bronchitis, arthritis, gastrointestinal disorders, liver or gall bladder problems, cataract, glaucoma, kidney diseases, gout, spin spur, and hip or other area fractures. Depressive symptoms were examined using the 10-item Center for Epidemiologic Studies Depression Scale (CES-D) [17]. Cognitive functions of participants were assessed using the recall test of a 10-word list and the digits backward test $[18,19]$. Social participation was defined as attending any volunteer or club activities, while social isolation was defined as living alone.

\section{Statistical analysis}

To identify distinct IADL disability trajectory groups, we used a generalized group-based trajectory model (GBT) to estimate trajectories of IADL disabilities and the probability of nonrandom dropout [20, 21]. IADL disability trajectories were estimated using a binary logistic model with age as the independent variable; nonrandom dropout was defined as death, whose probability was modeled as a function of IADL disability status at the survey wave prior to death [21]. Following Nagin [20], we choose the best fitting model based on the following criteria: the model with the lowest Bayesian Information Criteria value; and the model with the value of average posterior probabilities for each trajectory group $>0.7$.

We subsequently analyzed associations between participants' baseline characteristics and the identified IADL disability trajectory groups. Candidate factors were chosen using the following steps: first, we examined the associations of baseline variables with the trajectory groups using Chi-squared tests for categorical variables and independent t-tests for continuous variables.
Second, those factors significantly associated with the trajectory groups were used to establish multivariable logistic regressions where odds ratios with 95\% confidence interval were estimated.

Finally, in order to further examine the difference in disability-free life expectancy between the identified IADL disability trajectory groups, we used Sullivan's life table method [22], combining age-specific mortality rates with disability probability, to estimate the number of years of IADL disability-free life, IADL-disabled years, and the ratio of IADL disability-free years to total life expectancy. Age-specific disability probabilities were calculated using the results of the IADL disability trajectory analysis; accordingly, the identified trajectory groups were associated with different disability probabilities at specific ages. We used Gompertz models to estimate mortality rates [23]; the model was adjusted according to each trajectory group and sex. Total life expectancy can be divided into the number of IADL disability-free years, and years with IADL disability. For detailed computing methods, referred to Jagger et al. [24].

\section{Results}

At baseline, the mean age of 3118 participants (1901 male and 1217 female) was $60.7( \pm 7.9)$ years. Over half of participants were married (80.7\%), having no junior high school education or above (71.8\%), living in cities or suburbs $(62.9 \%)$, not employed (52.5\%), living in a house they owned (67.2\%), unsatisfied with their economic status $(61.0 \%)$, not living alone $(93.3 \%)$ and without social participation (53.1\%) (see Supplementary Table S1). About half of the participants' self-assessed health was good (48.2\%); in the past year, one in ten had a history of hospitalization. The most frequently reported health problems were hypertension (19.9\%), followed by gastrointestinal ulcer (12.8\%) and arthritis (12.6\%); the rest of health problems were reported less than $10 \%$ among participants. Among the participants, one-third of were smokers, $27.5 \%$ had habitual alcohol drinking, and less than $10 \%$ had chewed betel nuts; more than $90 \%$ were used to eating breakfast, but did not get enough exercise (66.5\%), i.e., three times a week and 30 minutes each time; $60 \%$ of them had not done a health check within three years. After the third year of followup, $19 \%$ of the participants had IADL disability; while in the seventh and eleventh years, the number of disabled people increased to $29 \%$ (Fig. 1).

Figure 2 illustrates the IADL disability trajectory groups representing the probability of IADL disability by age, estimated from the best-fitting model using the GBT method (Table 1). Two trajectory groups were identified: the late-onset group that was characterized by delayed IADL disability onset and the early-onset group characterized by early onset of disability. The late-onset 


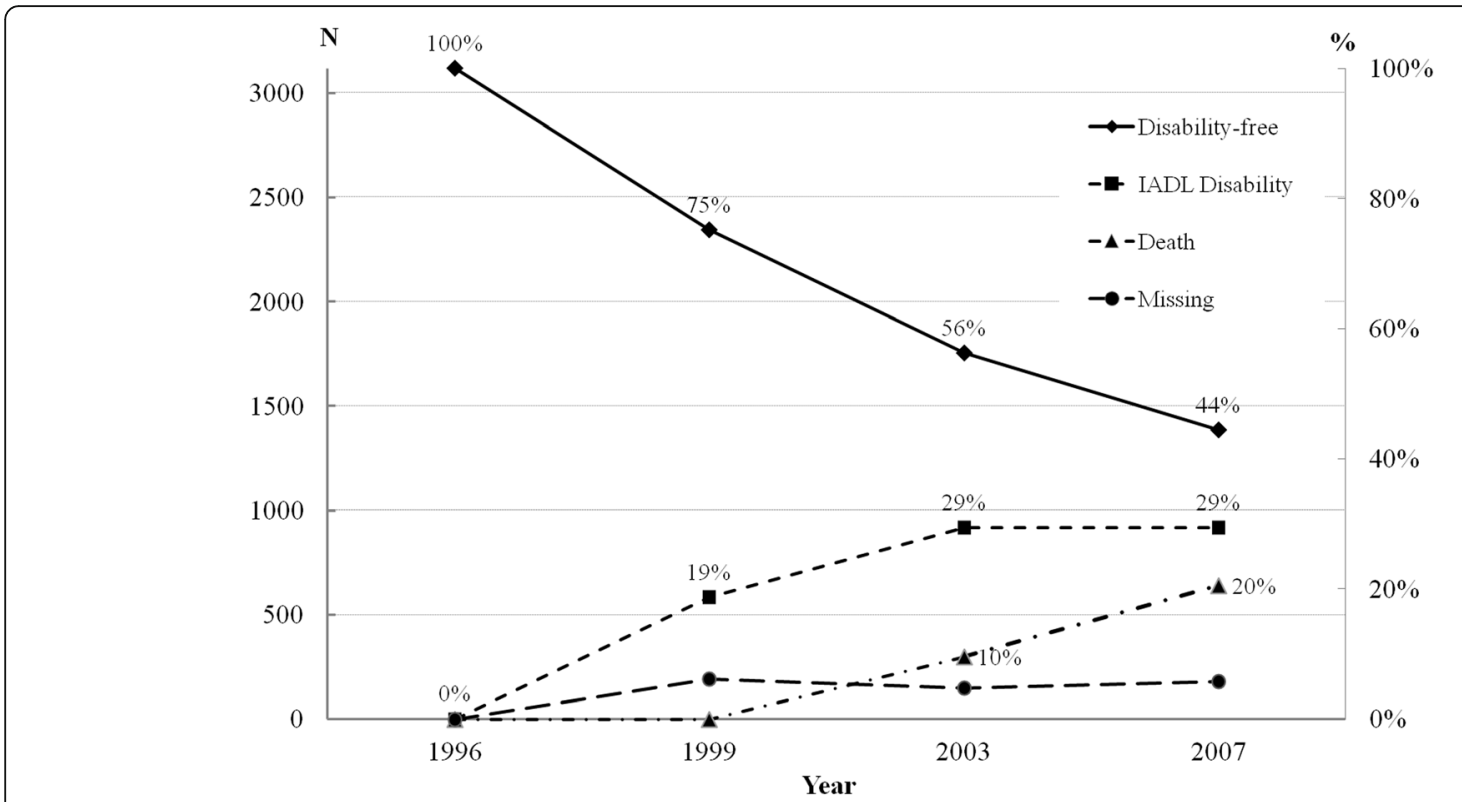

Fig. 1 Numbers and percentages of IADL disability, disability-free and death in study participants, 1996-2007. N=3118 at 1996; IADL: instrumental activity of daily life

trajectory includes an intercept and a linear scaled age parameter; in contrast, the early-onset group is a cubic polynomial of scaled age. The late-onset group's size was greater than that of the early-onset group (67.7 and $32.3 \%$, respectively). The probability of IADL disability increased continuously with age, independent of group membership. In the late-onset group, IADL disability became 25 and $50 \%$ likely at ages 77 and 82 years, respectively (a difference of 5 years). In contrast, in the early- onset group, these ages were 61 and 69 years, respectively (a difference of 8 years).

Table 2 presents the results of bivariate analysis and multivariate analysis. In bivariate analysis, participants in the early-onset group tended to be female, less educated, Hoklo, not employed, and unsatisfied with their economic status $(p<0.05)$. Regarding health status measures, participants in the early-onset group tended to have fair-to-poor self-rated health, be hospitalized in the

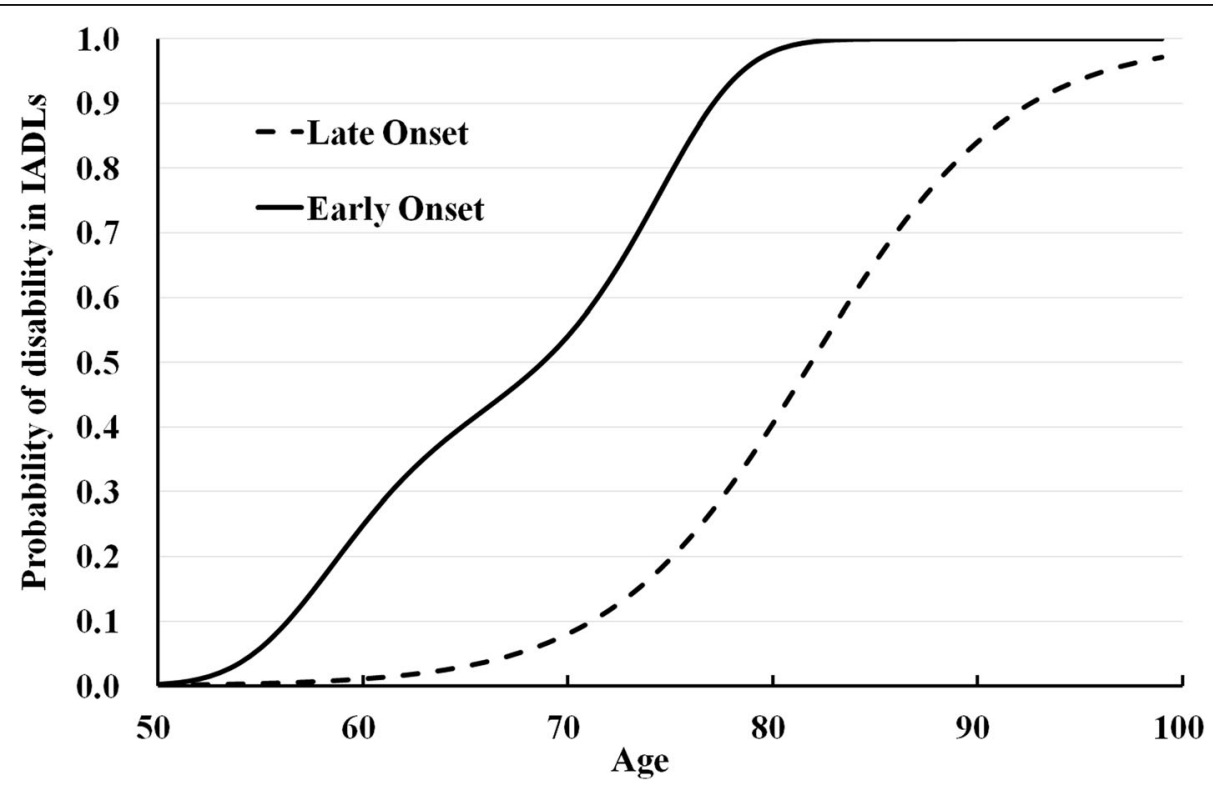

Fig. 2 Age trajectories of the probabilities of IADL disability by the late-onset and early-onset groups. Age trajectories were estimated using generalized group-based trajectory models 
Table 1 Results of logistic regressions for age trajectories of IADL disability among study participants

\begin{tabular}{lcl}
\hline & $\begin{array}{c}\text { Group 1 } \\
\text { Late onset }\end{array}$ & $\begin{array}{l}\text { Group 2 } \\
\text { Early onset }\end{array}$ \\
\hline Parameters for IADL disability trajectory & \\
Intercept & $-2.140(.127)^{*}$ & $0.399(.138)^{*}$ \\
Linear scaled age $^{\S}$ & $2.047(.098)^{*}$ & $1.873(.284)^{*}$ \\
Quadratic scaled age $^{\S}$ & & $1.685(.492)^{*}$ \\
Cubic scaled age & & $1.050(.240)^{*}$ \\
Group size (\%) & $67.66(2.867)^{*}$ & $32.34(2.867)^{*}$ \\
Average posterior probabilities & 0.88 & 0.81 \\
Bayesian Information Criterion $=-5132.56(\mathrm{~N}=3118)$ & \\
\hline
\end{tabular}

Note. Standard errors are in parentheses; ${ }^{*} p<.05 ;{ }^{5}$ Scaled age $=($ age -71.43$) /$ 10; Group size represents the estimated proportion of the population corresponding to each group; average posterior probabilities for each trajectory group were $>0.7$, indicating that the models were acceptable [20]

previous year, score lower (worse) in cognitive tests, score higher in CES-D (more depressive), or have a chronic disease, but were less likely to smoke, drink alcohol, exercise regularly, and attend volunteer or club activities $(p<0.05)$. Non-significant factors included house ownership, living area, marital status, betel nut chewing and breakfast habits, hearing impairment, cancer, bronchitis, cataract, and glaucoma.

The multivariate logistic regression analysis included only factors significantly associated with disability group membership in the bivariate analysis. Compared with the late-onset group, early-onset group members were more likely to be female (adjusted odds ratio [aOR]: 1.93, 95\% Confidence Interval [95\% CI]: 1.54, 2.41), not employed (aOR:1.30, 95\% CI: 1.08, 1.56), fair-to-poor self-rated health (aOR: 1.31, 95\% CI: 1.09, 1.58), and tended to have hypertension (aOR: 1.32, 95\% CI: 1.07 , 1.63), diabetes (aOR: 2.29, 95\% CI: 1.72, 3.07), strokes (aOR: $2.21,95 \%$ CI: 1.04, 4.70), arthritis (aOR: 1.42, 95\% CI: 1.11, 1.81), gout (aOR: 1.42, 95\% CI: 1.02, 1.98), spin spur (aOR: 1.57, 95\% CI: 1.12, 2.20), and hip fractures (aOR: 2.43, 95\% CI: 1.05, 5.60), and higher CES-D scores (aOR of a one-point increase: 1.04, 95\% CI: 1.02, 1.06). Participants were less likely to be in the early-onset group if they had education above senior high school (aOR: 0.59, 95\% CI: 0.42, 0.81), exercise $\geq 3$ times a week for over thirty minutes each time (aOR: $0.76,95 \% \mathrm{CI}$ : $0.62,0.93)$, or attended volunteer or club activities (aOR: 0.78, 95\% CI: 0.65, 0.93).

We examined group membership's effect on life expectancy by comparing the proportion of lifespan spent with IADL disability to total life expectancy at different ages for men and women (Table 3). At all ages, individuals in the late-onset group had a longer life expectancy as well as disability-free life expectancy than those in the early-onset group. Within each group, women had a higher life expectancy and disability-free life expectancy, but a lower ratio of disability-free life expectancy to life expectancy than men had. For example, women and men's ratios of disability-free life expectancy to life expectancy at 65 years old were 0.57 and 0.64 in the late-onset group, respectively, and 0.22 and 0.27 in the early-onset group. We can observe this sex difference at different ages (Fig. 3).

\section{Discussion}

This study examined a representative sample of individuals aged $\geq 50$ years in Taiwan to analyze trajectories of IADL disability from 1996 to 2007. This is the first study to analyze IADL disability trajectories from a point prior to disability incidence and using a model incorporating mortality. This study's key findings are as follows.

We identified two distinct IADL disability trajectory groups (late-onset and early-onset) representing respectively 67.7 and $32.3 \%$ of the population. Previous studies based on different study populations have identified three or more trajectory groups [2, 25-30]. The difference in numbers of trajectory groups may stem from different study populations, measurements of disability, or modelling methods. Compared with these studies, the current study did not identify a persistent or continuing disability group because of the exclusion of subjects with baseline disability that prevented a reverse causality between baseline correlates and the onset of IADL disability. Also, this study shows that the probability of disability increases with age regardless of the early onset or late onset of disability. No group of older people could live independently with their physical functions being not affected by increasing age in the long term, different from previous research $[2,25,29,30]$, yet consistent with LG Martin, Z Zimmer and J Lee [27]. This may be because the follow-up time of this study was long; those without physical limitations at baseline may eventually develop functional decline in the late period of follow-up.

Comparing probabilities of disability of two trajectory groups at ages between 50 and 70 years old, physical functions of early-onset group members deteriorated faster than those of late-onset group members. In addition, it took about 19 years for the prevalence of IADL disability to rise from 0 to $50 \%$ among early-onset group members, but the same change took 32 years among late-onset group members. This remarkable difference in time-to-onset suggests that if the onset of disability could be intervened to delay, the prevalence of disability would be reduced among older adults.

Our trajectory analysis indicated that it is possible to delay the onset of IADL disability through interventions targeting factors associated with early-onset disability. The current study found that participants who were not 
Table 2 Results of the bivariate and multivariate analysis to examine associations of baseline risk/preventive factors with trajectory groups among participants of the Taiwan Longitudinal Study in Aging ( $N=3118)$

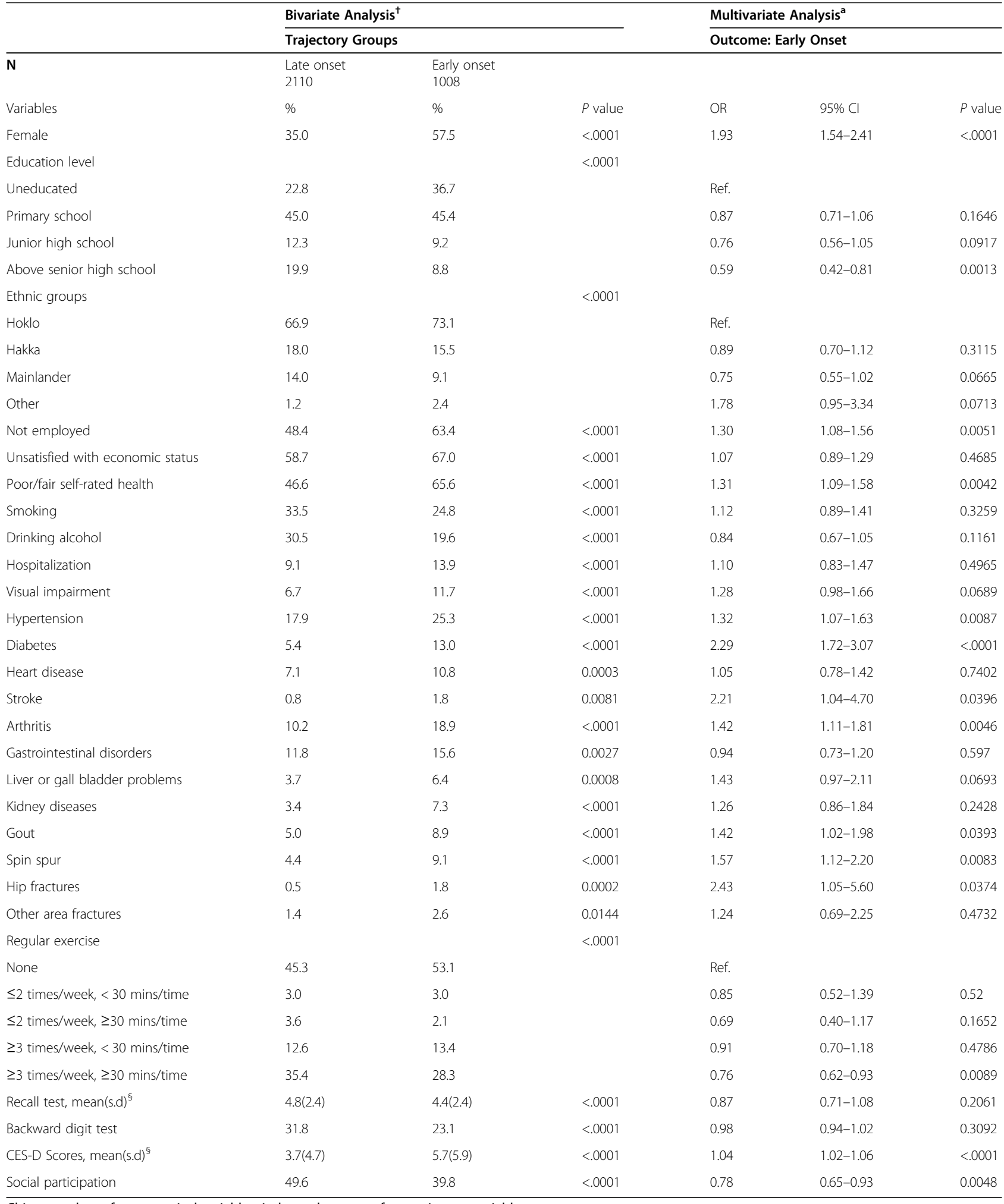

Chi-squared test for categorical variables; independent $t$ test for continuous variables

${ }^{a}$ Multiple logistic regressions; predicted outcome: early onset of IADL disability; OR odds ratio; 95\% CI 95\% confidence interval

Note: all calculations were weighted to compose a representative sample of Taiwan's population of individuals aged $\geq 50$ years; only baseline factors significantly associated with group membership are presented 
Table 3 Estimates of IADL disability-free life expectancy and their proportions to life expectancy at different ages

\begin{tabular}{|c|c|c|c|c|c|c|}
\hline \multirow[b]{2}{*}{ Age } & \multicolumn{3}{|l|}{ Men } & \multicolumn{3}{|l|}{ Women } \\
\hline & $\begin{array}{l}\text { Life Expectancy } \\
\text { (a) }\end{array}$ & $\begin{array}{l}\text { Disability-free Life } \\
\text { Expectancy (b) }\end{array}$ & (b)/(a) (\%) & $\begin{array}{l}\text { Life Expectancy } \\
\text { (a) }\end{array}$ & $\begin{array}{l}\text { Disability-free Life } \\
\text { Expectancy (b) }\end{array}$ & (b)/(a) (\%) \\
\hline \multicolumn{7}{|l|}{50 years old } \\
\hline Late-onset group & 35.7 & 28.1 & 78.6 & 41.4 & 29.7 & 71.8 \\
\hline Early-onset group & 29.3 & 16.3 & 55.5 & 34.8 & 17.0 & 48.7 \\
\hline \multicolumn{7}{|l|}{55 years old } \\
\hline Late-onset group & 31.1 & 23.4 & 75.1 & 36.6 & 24.9 & 68.0 \\
\hline Early-onset group & 24.9 & 11.7 & 46.8 & 30.2 & 12.2 & 40.4 \\
\hline \multicolumn{7}{|l|}{60 years old } \\
\hline Late-onset group & 26.6 & 18.8 & 70.5 & 32.0 & 20.2 & 63.0 \\
\hline Early-onset group & 20.8 & 7.7 & 36.9 & 25.8 & 8.1 & 31.2 \\
\hline \multicolumn{7}{|l|}{65 years old } \\
\hline Late-onset group & 22.4 & 14.4 & 64.2 & 27.5 & 15.6 & 56.6 \\
\hline Early-onset group & 16.9 & 4.6 & 27.2 & 21.6 & 4.8 & 22.5 \\
\hline
\end{tabular}

a Life expectancy at different ages was computed by life table where a mortality rate, $M$, at different ages, AGE, were estimated using Gompertz model: In $\left(M_{A G E, G R O U P, S E X}\right)=-11.247+0.099 \times A G E+0.689 \times$ GROUP $+(-0.592) \times$ SEX, where GROUP denotes trajectory group memberships $(0=$ late onset, $1=$ early onset $)$, and SEX is sex ( $1=$ female, $0=$ male)

employed, less educated, and experienced more depressive symptoms were more likely to have early-onset disabilities, whereas those who had sufficient exercise (three times or more per week for over thirty minutes each time) or attended club or volunteer activities were more likely to experience late-onset disabilities. The Report of the Second World Assembly on Aging [31] highlighted the importance of opportunities for employment in satisfying and productive work and having access to education and training courses that promote and protect working ability for older persons. Participating in paid or unpaid work can improve health in many dimensions, such as mortality, functional independence, and mental health [32-34], although there exist age and sex differences in the beneficial effect on physical functions [34]. Given an increasing older population, reemployment of older people may decrease the burden on society and delay the onset of disability, particularly as employment would increase an older person's opportunity for social participation [35], in turn reducing depressive symptoms [36]. The present results imply that policies or interventions to improve employment and social participation or reduce depression may prevent early-onset of IADL disability.

Compared with those with a lower level of engagement, participants who engaged in physical activities more than three times per week for more than thirty minutes each time significantly protected against earlyonset group membership. Our results are in concordance with several systematic review studies that confirmed the protective effect of exercise on functional decline or sarcopenia in later life [37-40]. This result also supports the exercise recommendation for older adults made by the American College of Sports Medicine and the American Heart Association (i.e., that older adults should perform moderate-intensity aerobic exercise for at least $30 \mathrm{~min}$, five days a week) [41]. However, some uncertainty remained regarding the required beneficial dosage (i.e., exercise types, intensity, frequency, and duration). The present results may therefore be used as a reference for exercise among middle-aged and older adults; however, future research should aim to determine optimal exercise patterns for middle-aged and older adults.

In bivariate analysis, lower performance in cognitive function, including digit backward test or recall test, had a significant association with early onset of IADL. However, after adjusting for other covariates, their significance diminished. There may be confounding factors, such as education or stroke that are related to both cognitive function and physical function. In addition, people with depression may show cognitive impairment on cognitive tests [42], and thus cognitive tests might not be able to distinguish cognitive impairment from depression [43]. Therefore, the association between cognitive function and IADL impairment may be attenuated when CES-D scores were adjusted for in the multivariate analysis.

The disability-free life expectancy at 65 years old for women and men in the late-onset group constituted 57 and $64 \%$ of their predicted remaining lifespan, whereas those figures in the early-onset group constituted 22 and $27 \%$ of their predicted remaining lifespan (Table 3). Japanese study estimated 65-year-old women and men's disability-free life expectancy at 14.6 and 12.8 years, respectively, constituting 70 and $74 \%$ of their remaining 


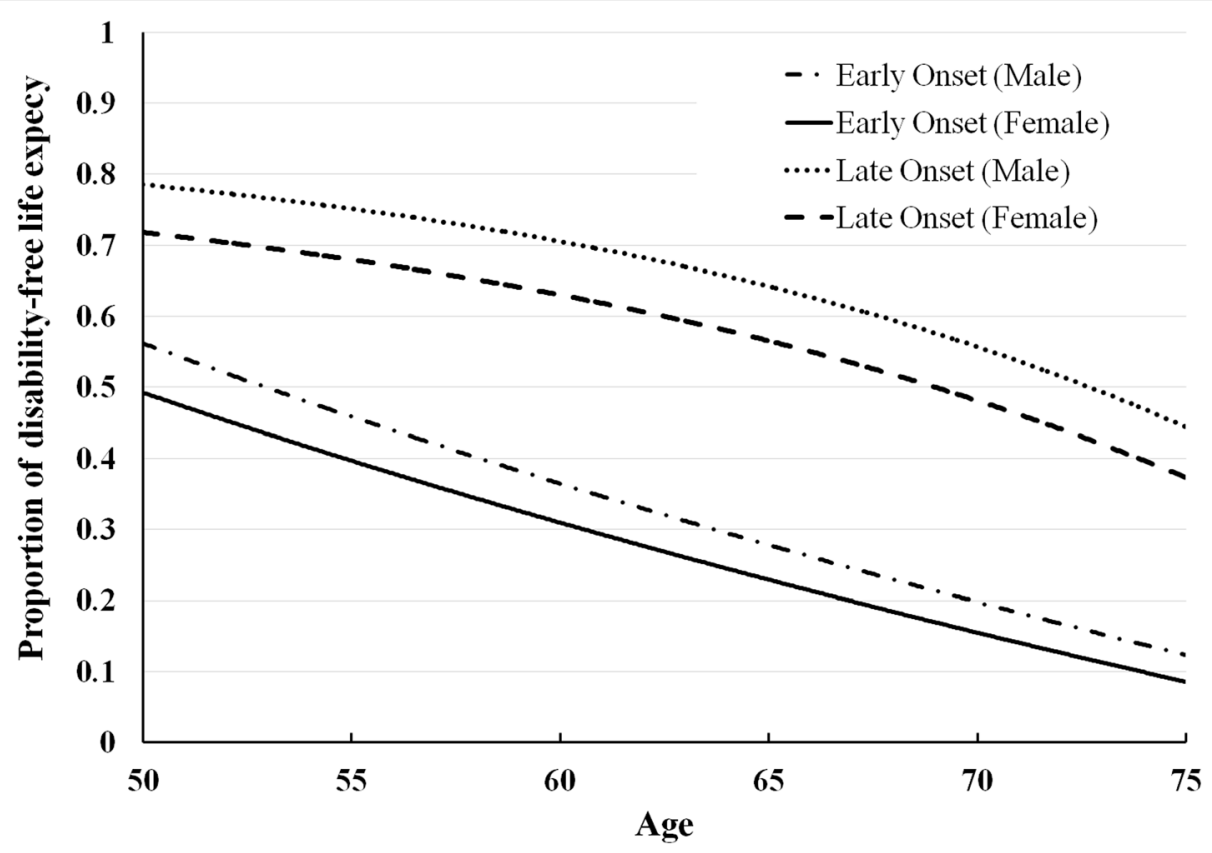

Fig. 3 Proportions of disability-free life expectancy to life expectancy at several ages for men and women

life [44]. In Italy, the proportion of IADL disability-free to life expectancy among men and women aged 65 years was 77 and 63\% [45]. The present figures for Taiwan were less than those for Japan and Italy. However, all these three studies revealed that men had a larger proportion of disability-free life expectancy, although women than men had a longer total life expectancy. Furthermore, regarding the two disability trajectory groups identified in this study, the late-onset group had a longer total life expectancy and a longer disability-free life expectancy. Improving population health through reducing comorbidities and promoting engagement in physical, social and economic activities would introduce a health transition from early-onset to late-onset of disability that achieves compression of morbidity [46, 47].

This study has the following limitations. First, due to the nature of the questionnaire, some factors associated with disability (e.g., compressive cognitive tests, falling history, body mass index, etc.) were not investigated. Second, the analyzed data has a 3-4-year survey window, and some transitions may not have manifested at the right time to be captured in one of the four waves. Third, IADL disability was defined as experiencing difficulty with any IADL task; however, age and sex may differentially affect onset of disability associated with specific IADL tasks that influence dependence of older persons in a different manner. Finally, the exclusion of participants who were IADL disabled at baseline that undermines the sample representativeness; therefore, the proportions of trajectory groups did not represent their prevalence in the population.

\section{Conclusions}

The present results indicate that IADL disability is not inevitable before very old ages. We identified several factors that may postpone IADL disability. Interventions that target individuals in middle age to compress the morbidity period and improve longevity are promising. This information from the study can aid in developing effective policies aimed to promote successful aging in the health transition of extended longevity.

\section{Supplementary Information}

The online version contains supplementary material available at https://doi. org/10.1186/s12877-020-01939-4.

Additional file 1 Supplementary Table $\mathbf{S} 1$ pdf, baseline characteristics of the participants of the Taiwan Longitudinal Study in Aging.

\section{Abbreviations}

ADL: Activity of Daily Life; BADL: Basic Activity of Daily Life;

IADL: Instrumental Activity of Daily Life; TLSA: The Taiwan Longitudinal Study in Aging; CES-D: The Center for Epidemiologic Studies Depression Scale; GBT: Group-Based Trajectory Model

\section{Acknowledgements}

This study used data from the TLSA which was provided and managed by the Health and Welfare Data Science Centre (HWDC), Ministry of Health and Welfare, Taiwan. The conclusions expressed here do not represent those of the administration. 


\section{Authors' contributions}

WLL collected and analyzed the data and was a major contributor in writing the manuscript. YHC conducted study design, interpreted the results and revised the manuscript. All authors read and approved the final manuscript.

\section{Funding}

The authors received no financial support for the research, authorship, and/ or publication of this article.

\section{Availability of data and materials}

The data that support the findings of this study are available from the Health and Welfare Data Science Center (HWDC), Ministry of Health and Welfare, Taiwan, but restrictions apply to the availability of these data, which were used under license for the current study, and so are not publicly available. However, data may be obtained with the permission of the HWDC, and data requests can be submitted to the HWDC as formal proposals (https://dep. mohw.gov.tw/dos/np-2497-113.html). Applicants must abide by the Personal Data Protection Act and the relevant regulations of the Ministry of Health and Welfare, Taiwan.

\section{Ethics approval and consent to participate}

The design of the study was approved by the Research Ethics Committee of China Medical University and Hospital, Taichung, Taiwan (CMUH-103REC3057); a waiver of consent was granted by the institutional review board. The use of TLSA data was approved and supervised by the Health and Welfare Data Science Center (HWDC), Ministry of Health and Welfare, Taiwan (No. H103094); all personally identifiable information of the TLSA participants were encrypted for patient protection.

\section{Consent for publication}

Not applicable.

\section{Competing interests}

The authors declare that they have no competing interests.

\section{Author details}

'Department of Physical Medicine and Rehabilitation, Taichung Tzu Chi Hospital, Buddhist Tzu Chi Medical Foundation, No. 66, Sec. 1, Fengxing Rd. Tanzi Dist., Taichung City 427, Taiwan. ${ }^{2}$ Department of Public Health, China Medical University, No. 100, Sec. 1, Jingmao Rd., Beitun Dist., Taichung City 406, Taiwan.

Received: 8 July 2020 Accepted: 30 November 2020 Published online: 09 December 2020

\section{References}

1. Liang J, Xu X, Bennett JM, Ye W, Quiñones AR. Ethnicity and changing functional health in middle and late life: a person-centered approach. J Gerontol B Psychol Sci Soc Sci. 2010;65(4):470-81. https://doi.org/10.1093/ geronb/gbq114.

2. Dodge HH, Du Y, Saxton JA, Ganguli M. Cognitive domains and trajectories of functional independence in nondemented elderly persons. J Gerontol A Bio/ Sci Med. Sci. 2006;61(12):1330-7. https://doi.org/10.1093/gerona/61.12. 1330.

3. Millán-Calenti JC, Tubío J, Pita-Fernández S, González-Abraldes I, Lorenzo T, Fernández-Arruty T, Maseda A. Prevalence of functional disability in activities of daily living (ADL), instrumental activities of daily living (IADL) and associated factors, as predictors of morbidity and mortality. Arch Gerontol Geriatr. 2010;50(3):306-10. https://doi.org/10.1016/j.archger.2009.04.017.

4. Cheung JTK, Yu R, Wu ZM, Wong SYS, Woo J. Geriatric syndromes, multimorbidity, and disability overlap and increase healthcare use among older Chinese. BMC Geriatr. 2018;18(1):147. https://doi.org/10.1186/s12877018-0840-1.

5. National Development Council. Population Projections for the Republic of China (Taiwan): 2018-2065. Available from: https://www.ndc.gov.tw/en/cp. aspx?n=2E5DCB04C64512CC\&s=002ABF0E676F4DB52018. Accessed 26th November 2020

6. World Health Organization (WHO). ICF: International classification of functioning, disability and health: short version. Geneva: WHO; 2001
7. Garman KS, Cohen HJ. Functional status and the elderly cancer patient. Crit Rev Oncol Hemat. 2002;43(3):191-208. https://doi.org/10.1016/S10408428(02)00062-8.

8. Lawton MP, Brody EM. Assessment of older people: self-maintaining and instrumental activities of daily living. Gerontologist. 1969;9(3_Part_1):179-86. https://doi.org/10.1093/geront/9.3_Part 1.179.

9. Judge JO, Schechtman K, Cress E, Group F. The relationship between physical performance measures and independence in instrumental activities of daily living. J Am Geriatr Soc. 1996;44(11):1332-41. https://doi.org/10. 1111/j.1532-5415.1996.tb01404.x.

10. Martin LG, Zimmer Z, Hurng BS. Trends in late-life disability in Taiwan, 1989-2007: the roles of education, environment, and technology. Popul Stud. 2011;65(3):289-304. https://doi.org/10.1080/00324728.2011.604730

11. Bowling CB, Deng L, Sakhuja S, Morey MC, Jaeger BC, Muntner P. Prevalence of activity limitations and association with multimorbidity among US adults 50 to 64 years old. J Gen Intern Med. 2019;34(11):2390-6. https://doi.org/10.1007/s11606-019-05244-8.

12. Forman-Hoffman $V L$, Ault KL, Anderson WL, Weiner JM, Stevens A, Campbell VA, Armour BS. Disability status, mortality, and leading causes of death in the United States community population. Med Care. 2015;53(4):346. https:// doi.org/10.1097/MLR.0000000000000321.

13. Freedman VA, Wolf DA, Spillman BC. Disability-free life expectancy over 30 years: a growing female disadvantage in the US population. Am J Public Health. 2016;106(6):1079-85. https://doi.org/10.2105/Ajph.2016.303089.

14. Freedman VA, Hodgson N, Lynn J, Spillman BC, Waidmann T, Wilkinson AM, Wolf DA. Promoting declines in the prevalence of late-life disability: comparisons of three potentially high-impact interventions. Milbank Q. 2006;84(3):493-520. https://doi.org/10.1111/j.1468-0009.2006.00456.x.

15. Chang M, Hermalin A. 1989 survey of health and living status of the elderly in Taiwan: questionnaire and survey design. Comparative Study of the Elderly in Four Asian Countries Research Report: No. 89-1. Ann Arbor: Population studies center, University of Michigan; 1989.

16. Chen YJ, Dai YT, Yang $C T$, Wang TJ, Teng YH. A review and proposal on patient classification in long-term care system. Taipei: Department of Health, Taiwan; 1995.

17. Andresen EM, Malmgren JA, Carter WB, Patrick DL. Screening for depression in well older adults: evaluation of a short form of the CES-D. Am J Prev Med. 1994;10(2):77-84. https://doi.org/10.1016/S0749-3797(18)30622-6.

18. Harris S, Dowson J. Recall of a 10-word list in the assessment of dementia in the elderly. Br J Psychiatry. 1982;141(5):524-7. https://doi.org/10.1192/bjp. 141.5.524

19. Emrani S, Libon DJ, Lamar M, Price CC, Jefferson AL, Gifford KA, Hohman TJ, Nation DA, Delano-Wood L, Jak A. Assessing working memory in mild cognitive impairment with serial order recall. J Alzheimers Dis. 2018;61(3): 917-28. https://doi.org/10.3233/JAD-170555.

20. Nagin DS. Group-based modeling of development. Cambridge: Harvard University Press; 2005.

21. Haviland AM, Jones BL, Nagin DS. Group-based trajectory modeling extended to account for nonrandom participant attrition. Sociol Methods Res. 2011:40(2):367-90. https://doi.org/10.1177/0049124111400041.

22. Sullivan DF. A single index of mortality and morbidity. HSMHA Health Reports. 1971:86(4):347.

23. Finch CE, Pike MC. Maximum life span predictions from the Gompertz mortality model. J Gerontol A Biol Sci Med Sci. 1996;51(3):B183-94. https:// doi.org/10.1093/gerona/51A.3.B183.

24. Jagger $\mathrm{C}$, Van Oyen $\mathrm{H}$, Robine J-M. Health expectancy calculation by the Sullivan method: a practical guide. 4th ed. Newcastle: University of Newcastle; 2014. Available from: http://www.eurohex.eu/pdf/Sullivan_ guide_pre\%20final_oct\%202014.pdf Accessed 26th November 2020.

25. Gill TM, Gahbauer EA, Lin H, Han L, Allore HG. Comparisons between older men and women in the trajectory and burden of disability over the course of nearly 14 years. J Am Med Dir Assoc. 2013;14(4):280-6. https://doi.org/10. 1016/j.jamda.2012.11.011.

26. Zimmer Z, Martin LG, Jones BL, Nagin DS. Examining late-life functional limitation trajectories and their associations with underlying onset, recovery, and mortality. J Gerontol B Psychol Sci Soc Sci. 2014;69(2):275-86. https:// doi.org/10.1093/geronb/gbt099.

27. Martin LG, Zimmer Z, Lee J. Foundations of activity of daily living trajectories of older Americans. J Gerontol B Psychol Sci Soc Sci. 2017:72(1): 129-39. https://doi.org/10.1093/geronb/gbv074.

28. Ferrante LE, Pisani MA, Murphy TE, Gahbauer EA, Leo-Summers LS, Gill TM. Functional trajectories among older persons before and after critical illness. 
JAMA Intern Med. 2015;175(4):523-9. https://doi.org/10.1001/ jamainternmed.2014.7889.

29. Jonkman NH, Del Panta V, Hoekstra T, Colpo M, van Schoor NM, Bandinelli S, Cattelani L, Helbostad JL, Vereijken B, Pijnappels M. Predicting trajectories of functional decline in 60-to 70-year-old people. Gerontology. 2018;64(3):212-21.

30. Hsu HC. Effects of physical function trajectories on later long-term care utilization among the Taiwanese elderly. Geriatr Gerontol Int. 2013;13(3): 751-8. https://doi.org/10.1111/j.1447-0594.2012.00964.x.

31. United Nations. Report of the Second World Assembly on Ageing. Madrid, 8-12 April 2002. New York: United Nations; 2002.

32. Stav WB, Hallenen T, Lane J, Arbesman M. Systematic review of occupational engagement and health outcomes among communitydwelling older adults. Am J Occup Ther. 2012;66(3):301-10. https://doi.org/ 10.5014/ajot.2012.003707.

33. van der Noordt M, IJzelenberg H, Droomers M, Proper KI. Health effects of employment: a systematic review of prospective studies. Occup Environ Med. 2014;71(10):730-6. https://doi.org/10.1136/oemed-2013-101891.

34. Tomioka K, Kurumatani N, Hosoi H. Age and gender differences in the association between social participation and instrumental activities of daily living among community-dwelling elderly. BMC Geriatr. 2017;17(1):99. https://doi.org/10.1186/s12877-017-0491-7.

35. Callander E, Schofield DJ. The relationship between employment and social participation among Australians with a disabling chronic health condition: a cross-sectional analysis. BMJ Open. 2013;3(1):e002054. https://doi.org/10 1136/bmjopen-2012-002054.

36. Croezen S, Avendano M, Burdorf A, van Lenthe FJ. Social participation and depression in old age: a fixed-effects analysis in 10 European countries. Am J Epidemiol. 2015;182(2):168-76. https://doi.org/10.1093/aje/kwv015.

37. Giné-Garriga M, Roqué-Fíguls M, Coll-Planas L, Sitja-Rabert M, Salvà A. Physical exercise interventions for improving performance-based measures of physical function in community-dwelling, frail older adults: a systematic review and meta-analysis. Arch Phys Med Rehabil. 2014;95(4):753-69. e753. https://doi.org/10.1016/j.apmr.2013.11.007.

38. Steffl M, Bohannon RW, Sontakova L, Tufano JJ, Shiells K, Holmerova I. Relationship between sarcopenia and physical activity in older people: a systematic review and meta-analysis. Clin Interv Aging. 2017;12:835-45. https://doi.org/10.2147/Cia.S132940

39. Chou C-H, Hwang C-L, Wu Y-T. Effect of exercise on physical function, daily living activities, and quality of life in the frail older adults: a meta-analysis. Arch Phys Med Rehabil. 2012;93(2):237-44. https://doi.org/10.1016/j.apmr. 2011.08.042.

40. Kidd T, Mold F, Jones C, Ream E, Grosvenor W, Sund-Levander M, Tingström P, Carey N. What are the most effective interventions to improve physical performance in pre-frail and frail adults? A systematic review of randomised control trials. BMC Geriatr. 2019;19(1):184. https:/doi.org/10.1186/s12877-019-1196-x.

41. Nelson ME, Rejeski WJ, Blair SN, Duncan PW, Judge JO, King AC, Macera CA, Castaneda-Sceppa C. Physical activity and public health in older adults: recommendation from the American College of Sports Medicine and the American Heart Association. Med Sci Sports Exerc. 2007;39(8):1435-45. https://doi.org/10.1161/CIRCULATIONAHA.107.185650.

42. Marazziti D, Consoli G, Picchetti M, Carlini M, Faravelli L. Cognitive impairment in major depression. Eur J Pharmacol. 2010;626(1):83-6. https:// doi.org/10.1016/j.ejphar.2009.08.046.

43. Coen R, Kirby M, Swanwick G, Maguire C, Walsh J, Coakley D, O'Neill D, Lawlor BA. Performance on the delayed word recall (DWR) fails to differentiate clearly between depression and Alzheimer's disease. Psychol Med 1998;28(2):495. doi: https://doi.org/10.1017/s0033291797216491.

44. Ishizaki T, Kai I, Kobayashi Y, Imanaka Y. Functional transitions and active life expectancy for older Japanese living in a community. Arch Gerontol Geriatr. 2002;35(2):107-20. https://doi.org/10.1016/S0167-4943(02)00002-X.

45. Minicuci $N$, Noale M. Disability free life expectancy in older Italians. Disabil Rehabil. 2005;27(5):221-7. https://doi.org/10.1080/09638280400006432.

46. Fries JF. Aging, natural death, and the compression of morbidity. N Engl J Med. 1980;303:130-5.

47. Andrews GR. Care of older people - promoting health and function in an ageing population. Brit Med J. 2001;322(7288):728-9. https://doi.org/10. 1136/bmj.322.7288.728.

\section{Publisher's Note}

Springer Nature remains neutral with regard to jurisdictional claims in published maps and institutional affiliations.

\section{Ready to submit your research? Choose BMC and benefit from:}

- fast, convenient online submission

- thorough peer review by experienced researchers in your field

- rapid publication on acceptance

- support for research data, including large and complex data types

- gold Open Access which fosters wider collaboration and increased citations

- maximum visibility for your research: over $100 \mathrm{M}$ website views per year

At BMC, research is always in progress.

Learn more biomedcentral.com/submissions 